\title{
Electroplated Fe-Ni films prepared from deep eutectic solvents
}

\author{
T. Yanai ${ }^{1}$, K. Shiraishi ${ }^{1}$, Y. Watanabe ${ }^{1}$, M. Nakano ${ }^{1}$, T. Ohgai $^{1}$, K. Suzuki ${ }^{2}$, and H.Fukunaga ${ }^{1}$, Member, IEEE \\ ${ }^{1}$ Guraduate School of Engineering, Nagasaki University, Nagasaki 852-8521, Japan \\ ${ }^{2}$ Department of Material Engineering, Monash University, Clayton VIC 3800, Australia
}

Fe-Ni alloy films were prepared by electroplating in a plating bath containing a choline chloride and ethylene glycol based deep eutectic solvent (DES). The Fe content of the electroplated films was found to vary from 0 to 100 at. \% and was dependent on the amount of Fe reagent in the plating bath. The composition of the electroplated films could be controlled easily by changing the composition of the bath. We observed bcc or fcc Fe-Ni crystalline phase in the electroplated films by $\mathrm{X}$-ray diffraction and confirmed that magnetically soft Fe-Ni alloy films could be obtained from the DES-based bath. The current efficiency for the plating process was as high as $>\mathbf{8 8} \%$ over a wide range of the Fe reagent concentrations. Therefore, we conclude that the DES is an attractive solvent for preparing the Fe-Ni alloy films.

Index Terms-Soft magnetic films, Electroplating, Permalloy, Deep Eutectic Solvent

\section{INTRODUCTION}

$\mathrm{E}$ lectroplating is one of useful techniques for obtaining thin and thick films, and aqueous solutions are commonly used for the magnetic films in a range of alloy systems such as FeNi, Fe-Co, Fe-Co-Ni, Fe-Pt and Co-Pt [1]-[7]. Recently, we have reported that a plating bath containing a choline chloride and ethylene glycol based deep eutectic solvent (DES) is hopeful for electroplating Fe films [8]. The DESs have many industrial advantages such as wide electrochemical window, extremely low vapor pressure, low cost, high purity, and low toxicity [9]-[11]. Therefore, the DESs are expected as a new solvent for the electroplating bath. Although there have been some reports on magnetic films of $\mathrm{Ni}, \mathrm{Co}$, Ni-Co, Ni-Co-Sn, Sm-Co and Co-Pt prepared from DES-based baths [12]-[18], Fe-based materials were rarely reported [19]. It is well-known that Fe-based alloys, such as Fe-Ni, Fe-Al-Si, Fe-Pt and NdFe-B are superior soft or hard magnetic materials and their electroplated films are useful for mass-productive electric devices. In this study, we have focused on soft magnetic Fe-Ni alloys and investigated the structural and the magnetic properties of the Fe-Ni films electroplated in DES-based plating baths with various compositions.

\section{EXPERIMENTAL PROCEDURE}

\section{A. Preparation of electroplated Fe-Ni films}

$\begin{array}{ccc}\text { We used a DES base on choline chloride } \\ \left(\mathrm{HOCH}_{2} \mathrm{CH}_{2} \mathrm{~N}\left(\mathrm{CH}_{3}\right)_{3} \mathrm{Cl}\right) & \text { and } & \text { ethylene }\end{array}$
( $\left.\mathrm{HOCH}_{2} \mathrm{CH}_{2} \mathrm{OH}\right)$ [8], [17], [20], [21] in the present study. The DES was prepared by stirring the mixture, which consists of $10 \mathrm{~g}$ of ethylene glycol and $10 \mathrm{~g}$ of choline chloride, at $100{ }^{\circ} \mathrm{C}$ until a homogeneous liquid state is obtained. $\mathrm{FeCl}_{2} \cdot 4 \mathrm{H}_{2} \mathrm{O}$ and $\mathrm{NiCl}_{2} \cdot 6 \mathrm{H}_{2} \mathrm{O}$ were added into this DES. The weight of $\mathrm{FeCl}_{2} \cdot$ $4 \mathrm{H}_{2} \mathrm{O}$ was altered from 0 to $15 \mathrm{~g}$, and the total weight of the reagents $\left(\mathrm{FeCl}_{2} \cdot 4 \mathrm{H}_{2} \mathrm{O}+\mathrm{NiCl}_{2} \cdot 6 \mathrm{H}_{2} \mathrm{O}\right)$ was kept at $15 \mathrm{~g}$ in this

Manuscript received March 7, 2014. Corresponding author: K. Shiraishi (e-mail: bb52114222 @cc.nagasaki-u.ac.jp).

Digital Object Identifier inserted by IEEE study. We didn't use any smoothing agents. The composition of the plating bath is shown in Table I. $500 \mu \mathrm{m}$-thick Ni and $\mathrm{Cu}$ plates were used as the anode and cathode electrodes, respectively. The distance between the electrodes was set at 20 $\mathrm{mm}$, and we obtained $75-\mathrm{mm}^{2} \mathrm{Fe}-\mathrm{Ni}$ films on the $\mathrm{Cu}$ plate. The bath temperature was kept at $100{ }^{\circ} \mathrm{C}$ and no stirring action was taken during the plating. The films were electroplated using a direct current. The current density and the plating time were controlled by a computer-aided dc current source. The plating conditions are shown in Table II.

TABLE I. COMPOSITION OF THE DES-BASED PLATING BATH

\begin{tabular}{cc}
\hline \hline Components & Weight (g) \\
\hline $\mathrm{FeCl}_{2} \cdot 4 \mathrm{H}_{2} \mathrm{O}$ & $x$ \\
$\mathrm{NiCl}_{2} \cdot 6 \mathrm{H}_{2} \mathrm{O}$ & $15-x$ \\
Choline chloride & 10 \\
Ethylene glycol & 10 \\
\hline \hline & \\
TABLE II. ELECTROPLATING CondiTIONS \\
\hline \hline Conditions & Value \\
\hline Bath temperature & $100{ }^{\circ} \mathrm{C}$ \\
Current density & $67 \mathrm{~mA} / \mathrm{cm}^{2}$ \\
Deposition time & $20 \mathrm{~min}$ \\
\hline \hline
\end{tabular}

\section{B. Measurements}

The thicknesses and the hysteresis loops of the electroplated films were measured with a micrometer (Mitutoyo CPM15$25 \mathrm{MJ}$ ) and a vibrating sample magnetometer (Tamagawa), respectively. The maximum applied field of approximately 1.6 $\mathrm{MA} / \mathrm{m}$ was used for the measurement of $\mathrm{M}-\mathrm{H}$ loops. The saturation magnetization and the coercivity of the electroplated films were determined from the $\mathrm{M}-\mathrm{H}$ loops. The compositions and the crystal structures of the films were analyzed by EDX (Hitachi High-technologies S-3000) and XRD (Rigaku Rint 2000), respectively. The thickness and the composition of each $75 \mathrm{~mm}^{2}$-film were determined by averaging the values obtained for approximately every $9 \mathrm{~mm}^{2}$ (9 points). The current efficiency was calculated from the actual weight of the electroplated film and the theoretical weight obtained by Faraday's law. For the calculation of the theoretical weight, we used the evaluated film composition. 


\section{RESUlTS AND DISCUSSION}

Figure 1 shows the changes in Fe content and current efficiency of the electroplated Fe-Ni films as a function of amount of the Fe reagent $\left(\mathrm{FeCl}_{2} \cdot 4 \mathrm{H}_{2} \mathrm{O}\right)$ in the bath. The films shown in Fig. 1 have almost the same thickness of approximately $22 \mu \mathrm{m}$, and we have already confirmed the good homogeneity of the composition in the depth direction for the Fe-Ni films. The Fe content increases linearly with the Fe reagent content, indicating that the composition of the Fe$\mathrm{Ni}$ films can be controlled by adjusting the reagent content in the plating bath. The current efficiency shows high values (> $88 \%$ ) in a wide range of the Fe reagent content. Therefore, it is found that Fe-Ni films with various Fe compositions could be obtained quite efficiently from the DES-based plating bath.

Figure 2 shows the hysteresis loops of the films electroplated from the bath with various Fe reagent content. As shown in Fig. 2, the saturation magnetizations of the films varied with the amount of the Fe reagent in the DES-based plating bath. In order to investigate the changes in the saturation magnetization systematically, we evaluated the effect of the amount of the Fe reagent on magnetic properties of the films. Figure 3 shows the changes in the saturation magnetization and coercivity of the electroplated Fe-Ni films as a function of the $\mathrm{Fe}$ reagent content. The saturation magnetization shows a linier increase with increasing the reagent content. The change in the saturation magnetization could be explained by the $\mathrm{Fe}$ content in the films. The coercivity drastically decreases with increasing the Fe reagent from 0 to $5 \mathrm{~g}$ followed by a slight increase in the higher amount of the Fe reagent. As shown in Fig.1, the Fe content of the film electroplated in the bath with the Fe reagent of $5 \mathrm{~g}$ was approximately 26 at. \%. Since both the magnetocrystalline anisotropy and the magnetostriction constants in the Fe-Ni binary system become nearly zero at $\mathrm{Fe}_{22} \mathrm{Ni}_{78}$, the drastic decrease in coercivity is attributable to the suppression of the intrinsic magnetic and magneto-elastic anisotropy values.

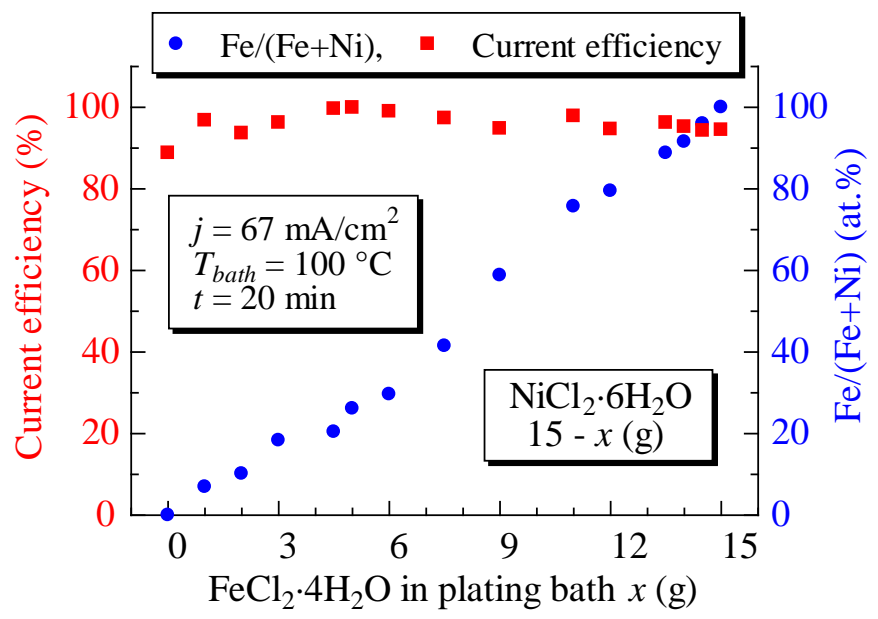

Fig.1 Fe content and current efficiency of the electroplated Fe-Ni films as a function of amount of the Fe reagent $\left(\mathrm{FeCl}_{2} \cdot 6 \mathrm{H}_{2} \mathrm{O}\right)$ in the DES-based plating bath.

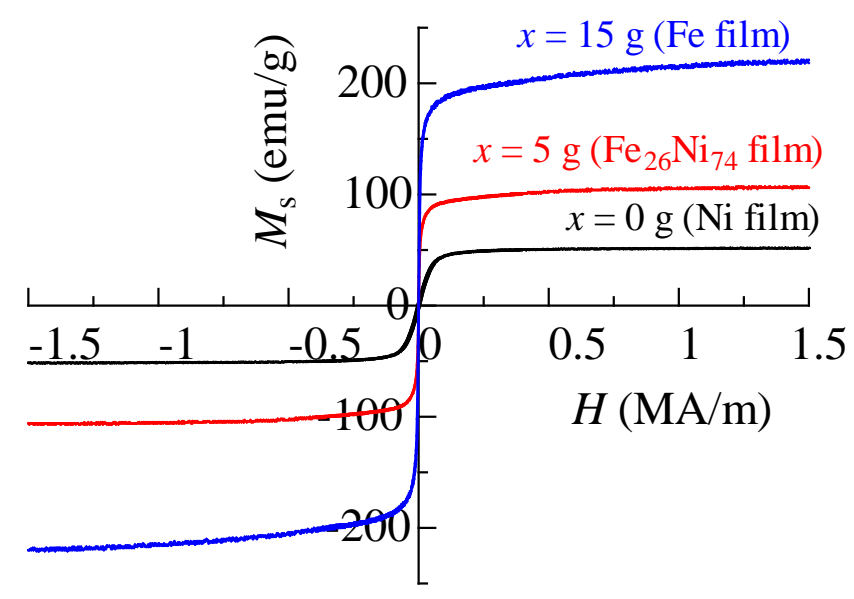

Fig.2 Hysteresis loops of the electroplated $\mathrm{Ni}, \mathrm{Fe}_{26} \mathrm{Ni}_{74}$ and $\mathrm{Fe}$ films.

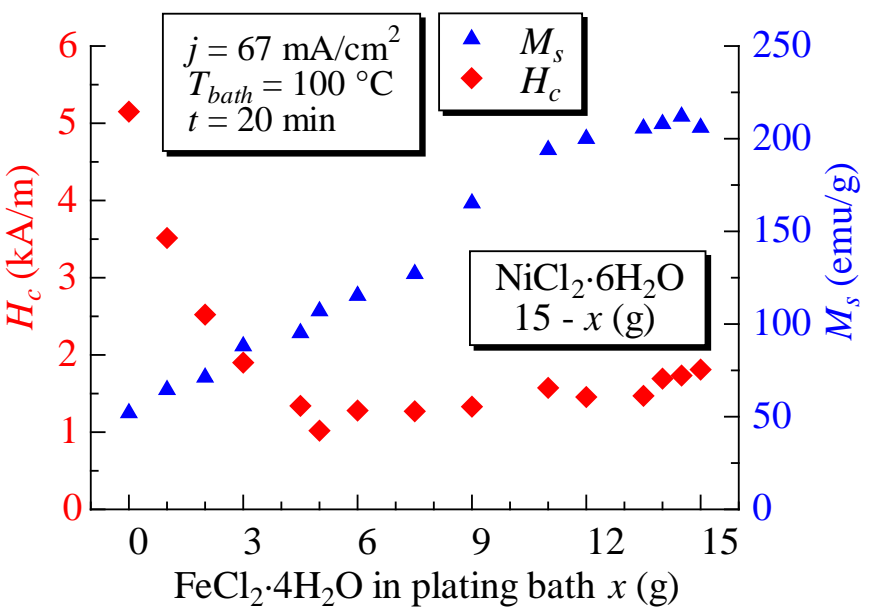

Fig.3 Coercivity $H_{c}$ and saturation magnetization $M_{s}$ of the electroplated Fe-Ni films as a function of amount of the Fe reagent $\left(\mathrm{FeCl}_{2} \cdot 6 \mathrm{H}_{2} \mathrm{O}\right)$ in the DESbased plating bath.

Figure 4 shows surface morphologies of the $\mathrm{Ni}, \mathrm{Fe}_{26} \mathrm{Ni}_{74}$ and Fe films. As shown in Fig. 4, the Ni film had a rough surface compared with those for the $\mathrm{Fe}_{26} \mathrm{Ni}_{74}$ and Fe films. In general, since rough surface prevents magnetic domain wall movement during technical magnetization processes, soft magnetic properties of films with a rough surface are inferior to those for films with a smooth surface. Therefore, we considered that the improvement in the rough surface is one of other reasons for the observed drastic decrease in the coercivity.

In order to confirm the crystal structures of the Fe-Ni films, we carried out X-ray diffraction experiments for the electroplated films. Figure 5 shows the XRD patterns of the electroplated Fe-Ni films with various $\mathrm{Fe}$ contents. The diffraction peaks of fcc or bcc Fe-Ni crystalline phases were observed. The result for the X-ray analysis suggests that that the structure of the films depends on the Fe content. It is wellknown that the structure of the Fe-Ni binary system alloy depends on the Fe content [22]. The boundary composition between fcc and bcc structures is approximately $\mathrm{Fe}_{70} \mathrm{Ni}_{30}$ for the Fe-Ni binary alloy system. As shown in Fig. 5, the boundary was observed between $\mathrm{Fe}_{52} \mathrm{Ni}_{48}$ and $\mathrm{Fe}_{76} \mathrm{Ni}_{24}$, the composition for the phase transformation agrees with that for 
the Fe-Ni binary alloy system.

From above-mentioned results, we found that the DES-based bath enables us to obtain Fe-Ni alloy films with high current efficiency.

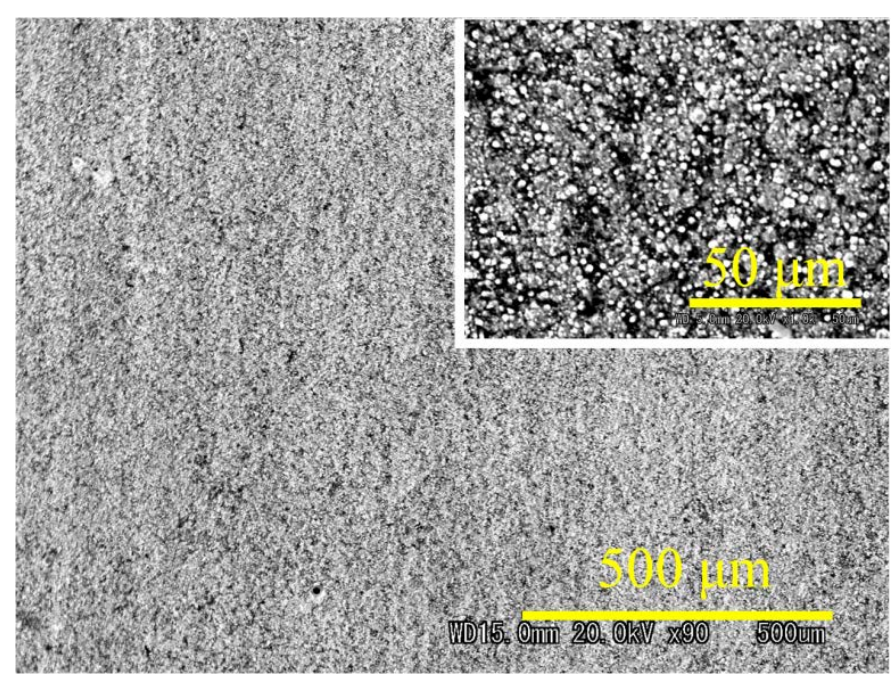

(a) Ni film (Thickness: $21 \mu \mathrm{m}$ )

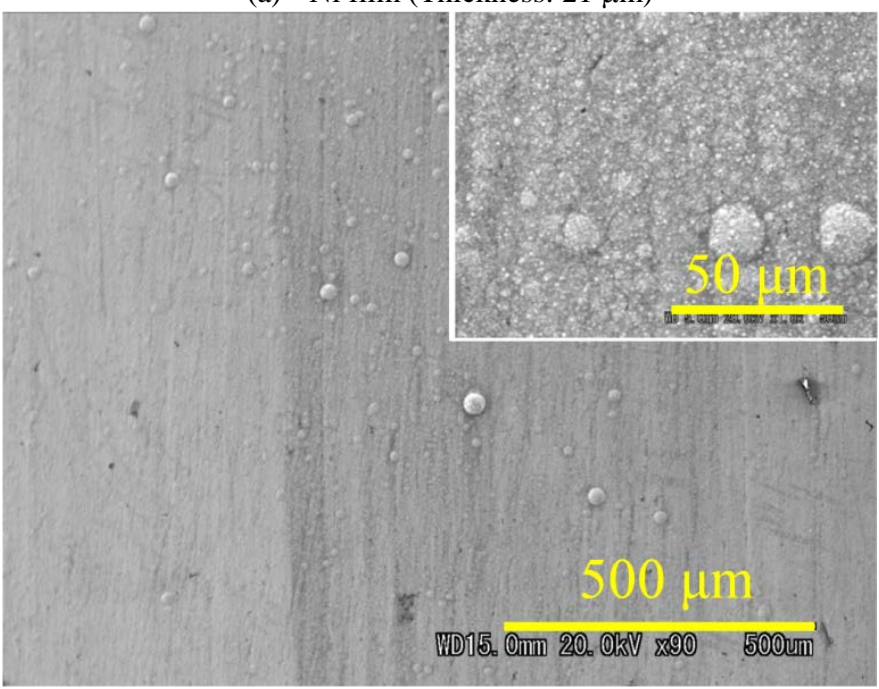

(b) $\mathrm{Fe}_{26} \mathrm{Ni}_{74}$ film (Thickness: $23 \mu \mathrm{m}$ )

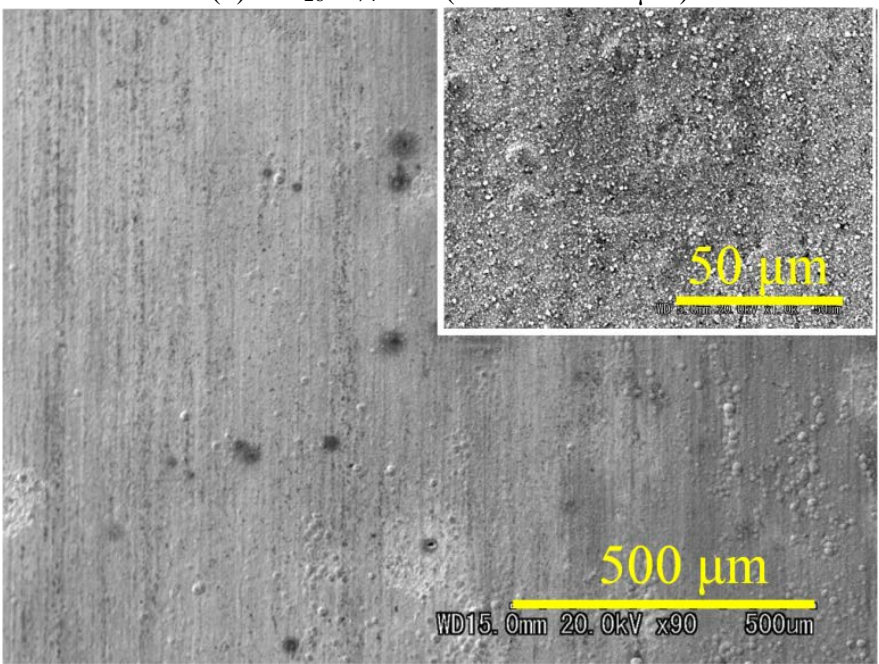

(c) Fe film (Thickness: $22 \mu \mathrm{m}$ )

Fig.4 Surface morphologies of the (a) $\mathrm{Ni}$, (b) $\mathrm{Fe}_{26} \mathrm{Ni}_{74}$ and (c) Fe films.

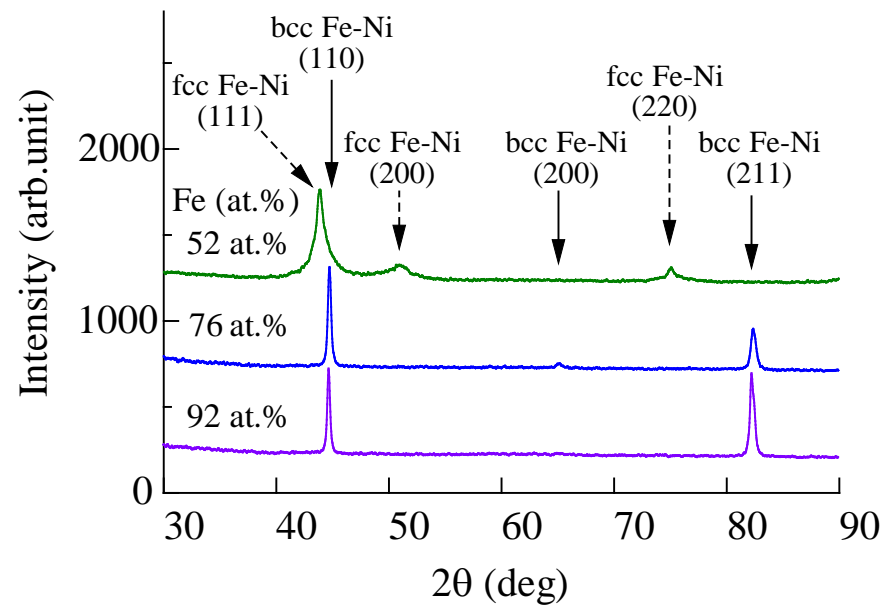

Fig.5 XRD patterns of the films prepared from the DES-based plating bath.

\section{CONCLUSION}

In this study, we electroplated Fe-Ni films in a DES-based bath and investigated the structural and magnetic properties of the films. The obtained results are summarized as follows:

(1) The Fe content in the electroplated films depended on the amount of the Fe reagent in the plating bath and adjusting the bath reagent composition is an easy way to control the film composition.

(2) The current efficiency showed high values of over $88 \%$ in a wide range of the Fe reagent content.

(3) The saturation magnetization of the film increased proportionally with increasing the Fe reagent, and the coercivity drastically decreases with increasing the $\mathrm{Fe}$ reagent from 0 to $5 \mathrm{~g}$. The drastic decrease in the coercivity is attributed to the reduction in the magnetocrystalline anisotropy and the magnetostriction constants of the film.

(4) Bcc or fcc Fe-Ni crystalline phase was observed in the result for the X-ray analysis, and we confirmed the phase transformation from the fcc structure to the bcc one in the Fe content range from 52 to 76 at.\%.

We concluded that the choline chloride-ethylene glycol based DES is one of hopeful solvents for electrodeposition of Fe-Ni alloy films.

\section{REFERENCES}

[1] T. Shimokawa, T. Yanai, K. Takahashi, M. Nakano, K. Suzuki, and H. Fukunaga, "Soft Magnetic Properties of Electrodeposited Fe-Ni Films Prepared in Citric Acid Based Bath,” IEEE Trans. Magn., vol. 48, pp. 2907-2909, 2012.

[2] C. Qiang, J. Xu, S. Xiao, Y. Jiao, Z. Zhang, Y. Liu, L. Tian, and Z. Zhou, "The influence of $\mathrm{pH}$ and bath composition on the properties of $\mathrm{Fe}-\mathrm{Co}$ alloy film electrodeposition,” Appl. Surf. Sci., vol 257, pp. 1371-1376, 2010.

[3] T. Yanai, H. Uto, T. Shimokawa, M. Nakano, K. Suzuki, and H. Fukunaga, "Electrodeposited Fe-Co Films Prepared from a Citric-acidbased Plating Bath,” J. Kor. Phys. Soc., vol. 62, pp. 1966-1968, 2013. 
[4] T. Osaka, M. Takai, K. Hayashi, K. Ohashi, M. Saito, and K. Yamada, "A soft magnetic CoNiFe film with high saturation magnetic flux density and low coercivity," Nature, vol. 392, pp.796-798, 1998.

[5] G. Zangari, P. Bucher, N. Lecis, P. L. Cavallotti, L. Callegaro,and E. Puppin, "Magnetic properties of electroplated Co-Pt films," J. Magn. Magn. Mater., vol. 157/158, pp. 256-257, 1996.

[6] Fernand M. F. Rhen, G. Hinds, C. O'Reilly, and J. M. D. Coey, "Electrodeposited FePt Films," IEEE Trans. Magn., vol. 39, pp. 26992701, 2003.

[7] N. Fujita, S. Maeda, S. Yoshida, M. Takase, M. Nakano, and H. Fukunaga, "Preparation of Co-Pt alloy film magnets by electrodeposition,” J. Magn. Magn. Mater., vol. 272-276, pp. e1895e1897, 2004.

[8] T. Yanai, T. Shimokawa, Y. Watanabe, T. Ohgai, M. Nakano, K. Suzuki, and H. Fukunaga, "Electroplated Fe films prepared from a deep eutectic solvent," J. Appl. Phys., vol. 115, pp. 17A344 - 17A344-3, 2014.

[9] A.P. Abbott, D. Bothby, G. Capper, D.L. Davies, and R. Rasheed, "Deep Eutectic Solvents Formed between Choline Chloride and Carboxylic Acids: Versatile Alternatives to Ionic Liquids,” J. Am. Chem. Soc., vol. 126, pp. 9142-9147, 2004.

[10] A.P. Abbott, G. Capper, D.L. Davies, R.K. Rasheed, and V. Tambyrajah, "Novel Solvent Properties of Choline Chloride/ Urea Mixtures," Chem. Commun., vol. 9, pp. 70-71, 2003.

[11] A.P. Abbott, G. Capper, D.L. Davies, K.J. McKenzie, and S.U. Obi, "Solubility of Metal Oxides in Deep Eutectic Solvents Based on Choline Chloride," J. Chem. Eng. Data, vol. 51, pp. 1280-1282, 2006.

[12] E. Gómez, P. Cojocaru, L. Magagnin, and E. Valles, "Electrodeposition of Co, Sm and SmCo from a Deep Eutectic Solvent," J. Electroanal. Chem., vol. 658, pp. 18-24, 2011.

[13] P. Cojocaru, L. Magagnin, E. Gómez, and E. Valles, "Using deep eutectic solvents to electrodeposit CoSm films and nanowires," Mater. Lett., vol. 65, pp.3597-3600, 2011.

[14] H. Yang, X. Guo, N. Birbilis, G. Wu, and W. Ding, "Tailoring nickel coatings via electrodeposition from a eutectic-based ionic liquid doped with nicotinic acid,” Appl. Surf. Sci., vol. 257, pp. 9094-9102, 2011.

[15] P. Guillamat, M. Cortés, E. Vallés, and E. Gómez, "Electrodeposited CoPt films from a deep eutectic solvent," Surf. Coat. Technol., vol. 206, pp. 4439-4448, 2012.

[16] G. Saravanan and S. Mohan, "Structure, composition and corrosion resistance studies of $\mathrm{Co}-\mathrm{Cr}$ alloy electrodeposited from deep eutectic solvent (DES),” J. Alloys Comp., vol. 522, pp. 162-166, 2012.

[17] Y.H. You, C.D. Gu, X.L. Wang, and J.P. Tu, "Electrodeposition of NiCo alloys from a deep eutectic solvent," Surf. Coat. Technol., vol. 206, pp. 3632-3638, 2012.

[18] J. Vijayakumar, S. Mohan, S.A. Kumar, S.R. Suseendiran, and S. Pavithra, "Electrodeposition of NieCoeSn alloy from choline chloridebased deep eutectic solvent and characterization as cathode for hydrogen evolution in alkaline solution," Int. J. Hydrogen Energy, vol. 38, pp. 10208-10214, 2013.

[19] F. Zhao, S. Franz, A. Vicenzo, M. Bestetti, F. Venturini, and P.L. Cavallotti, "Electrodeposition of $\mathrm{Fe}-\mathrm{Ga}$ thin films from eutectic-based ionic liquid,” Electrochimica Acta, vol. 114, pp. 878-888, 2013.

[20] A.P. Abbott, G. Capper, K.J. McKenzie, and K.S. Rayder, "Electrodeposition of Zinc Tin Alloys from Deep Eutectic Solvents Based on Choline Chloride," J. Electroanal. Chem., vol. 599, pp. 2882942007.

[21] C.D. Gu, Y.H. You, Y.L. Yu, S.X. Qu and J.P. Tu, "Microstructure, nanoindentation, and electrochemical properties of the nanocrystalline nickel film electrodeposited from choline chloride-ethylene glycol,” Surf. Coat. Technol., vol. 205, pp. 4928-4933, 2011.

[22] R.M. Bozorth “Ferromagnetism” Wiley-IEEE Press, pp. 102-103, 1993. 